\title{
Microstructural evolution of Al-Cu-Li alloys with different Li contents by coupling of near-rapid solidification and two-stage homogenization treatment
}

\author{
Lei Luo, Liang-shun Luo, Zhi-ping Li, Hong-ying Xia, *Yan-qing Su, Liang Wang, Jing-jie Guo, Heng-zhi Fu \\ School of Materials Science and Engineering, Harbin Institute of Technology, Harbin 150001, China
}

\begin{abstract}
Microstructural improvement of Al-Cu-Li alloys with high Li content plays a critical role for the acquisition of excellent mechanical properties and ultra-low density. In this regard, the Al-Cu-Li alloy castings with high Li content from $1.5 \mathrm{wt} . \%$ to $4.5 \mathrm{wt}$. \% were prepared by near-rapid solidification, followed by two-stage homogenization treatment $\left(490{ }^{\circ} \mathrm{C} / 16 \mathrm{~h}\right.$ and $\left.530{ }^{\circ} \mathrm{C} / 16 \mathrm{~h}\right)$. The microstructural evolution and solidification behavior of the as-cast and homogenized alloys with different $\mathrm{Li}$ contents were systematically studied by combining experiments with calculations by Pandat software. The results indicate that with the increase of $\mathrm{Li}$ content, the grain sizes decrease, the solution ability of $\mathrm{Cu}$ in the matrix $\alpha$-Al phase increases, while the content of secondary dendrites increases and the precipitated phases change from low melting point phases to high melting point phases under the near-rapid solidification. Additionally, by the coupling of near-rapid solidification and two-stage homogenization, the metastable precipitated phases $\left(\mathrm{Al}_{7} \mathrm{Cu}_{4} \mathrm{Li}\right.$ and $\left.\mathrm{AlCu}_{3}\right)$ can be dissolved effectively in the alloys with Li content of $1.5 \mathrm{wt} . \%-2.5 \mathrm{wt} . \%$; moreover, the stable precipitated phases $\left(\mathrm{Al}_{6} \mathrm{CuLi}_{3}\right.$ and $\mathrm{Al}_{2} \mathrm{CuLi}$ ) uniformly distribute at the grain boundaries in the alloys with $\mathrm{Li}$ content of $3.5 \mathrm{wt} . \%-4.5 \mathrm{wt} . \%$. As a result, the refined and homogenized microstructure can be obtained.
\end{abstract}

Key words: Al-Cu-Li alloys; ultra-low density; near-rapid solidification; two-stage homogenization treatment; microstructural evolution

CLC numbers: TG146.21 Document code: A Article ID: 1672-6421(2020)03-190-08

\begin{abstract}
A present, Al-Li alloys, owing to their light weight, recyclability, high strength, hardness, and elastic modulus, have gradually become potential structural materials applied in aerospace and other fields ${ }^{[1-5]}$. Related studies have shown that every $1 \%$ addition of Li content can effectively reduce the density about $3 \%$ and increase the elastic modulus around $6 \%$ in $\mathrm{Al}$ Li alloys ${ }^{[6,7]}$. However, when Li content increases too much, many adverse effects will be produced, such as drastic anisotropy and element segregation. In this case, under the solution and aging treatment, the refined $\delta$ phases are consumed, and the coarse $\delta$ phases will be accumulated at the grain boundaries, which seriously reduces the fracture toughness of the alloys ${ }^{[8]}$. At present, the main methods for the purpose of improving
\end{abstract}

\footnotetext{
*Yan-qing Su

Male, Ph.D, Professor. His research interests mainly focus on the development and preparation of new materials, solidification theory, and special casting technology. To date, he has published 4 books and more than 310 papers, and holds 27 invention patents of China.

E-mail: suyq@hit.edu.cn
}

Received: 2020-01-07; Accepted: 2020-04-27 the microstructure and properties of Al-Li alloys are micro-alloying, heat treatment, and special casting processes. For example, Xu et al. ${ }^{[9]}$ added Sc element into $2099 \mathrm{Al}-\mathrm{Li}$ alloys to strengthen the alloys by producing quantities of dislocations during the solution treatment. Wu et al. ${ }^{[10]}$ indicated that the hardness of $\mathrm{Al}-$ $\mathrm{Li}$ alloys with high $\mathrm{Li}$ content can be increased greatly by reasonable aging treatment. In addition, Balducci et al. ${ }^{[11]}$ and Zhang et al ${ }^{[12]}$ demonstrated that during the two-stage homogenization heat treatment, the low-melting eutectic phase containing $\mathrm{Cu}, \mathrm{Zn}, \mathrm{Mg}, \mathrm{Ag}$ and other elements could be dissolved followed by the dissolution of $\mathrm{Al}_{2} \mathrm{Cu}$ phase in 2055 and 2099 Al-Li alloys. Shanmugasundram et al. ${ }^{[13]}$ and Kim et al. ${ }^{[14]}$ significantly improved the strength and toughness of the alloys by aging treatment after extensive plastic deformation. Deng et al. ${ }^{[15]}$ prepared $\mathrm{Al}$ alloys in low temperature rolling and then increased the strength and toughness of the alloys by aging treatment. Moreover, Yang et al. ${ }^{[16]}$ and Wang et al. ${ }^{[17]}$ found that the recrystallization at high temperature can effectively change the microstructural evolution and anisotropy of 2A97 Al-Li alloys Although rapid solidification is commonly used to 
refine the microstructural sizes of alloys ${ }^{[18,19]}$, the complexity and limitations of this process make it more suitable for smalldimension materials, such as thin films and powder ${ }^{[20]}$. In contrast, the near-rapid solidification process is easier to achieve and can be applied to commercial quantities ${ }^{[21,22]}$. However, current studies mainly focus on Al-Li alloys with low Li content $(<1.8 \mathrm{wt} . \%)$; rarely on the microstructural evolution and solidification behavior of Al-Li alloys with higher Li content (>2wt.\%). As a result, there is a great obstacle in acquiring AlLi alloys with ultra-low density, due to the difficulty of research and the few available references.

Accordingly, in this study, the near-rapid solidification coupling with the two-stage homogenization heat treatment was performed to optimize the microstructure of $\mathrm{Al}-\mathrm{Cu}-\mathrm{Li}$ alloys with high Li contents from $1.5 \mathrm{wt} . \%$ to $4.5 \mathrm{wt} . \%$. Meanwhile, the analysis of microstructural evolution and solidification behavior for the as-cast and homogenized alloys was conducted by the combination of experiments and calculations by Pandat software. The current findings have elaborated in detail the process of microstructural evolution for the Al-Cu-Li alloys with different Li contents, and lay a foundation for obtaining AlLi alloys with ultra-low density.

\section{Experimental procedure}

The Al-Cu-Li alloys were prepared by the near-rapid solidified device as shown in Fig. 1. Raw materials of pure Al (with high purity of $99.99 \mathrm{wt} . \%$ ), pure $\mathrm{Li}$ (with electronic purity) and the master alloys of $\mathrm{Al}-\mathrm{Mg}, \mathrm{Al}-\mathrm{Zn}, \mathrm{Al}-\mathrm{Cu}$, and $\mathrm{Al}-\mathrm{Zr}$ were used for the preparation of the alloys. Firstly, high-purity $\mathrm{Al}$ was melted at $710{ }^{\circ} \mathrm{C}$ in an electric resistance furnace, followed by the addition of $\mathrm{Cu}, \mathrm{Zn}, \mathrm{Zr}$ and $\mathrm{Mg}$. The alloy melt was degassed by hexachloroethane and high purity argon. Then the Li element was added with anhydrous lithium chloride as the coating agent and Al-5Ti-1B as the refiner. After all the alloy elements were completely melted, the alloy melt was poured into the nearrapid solidification device. During the solidification process, the

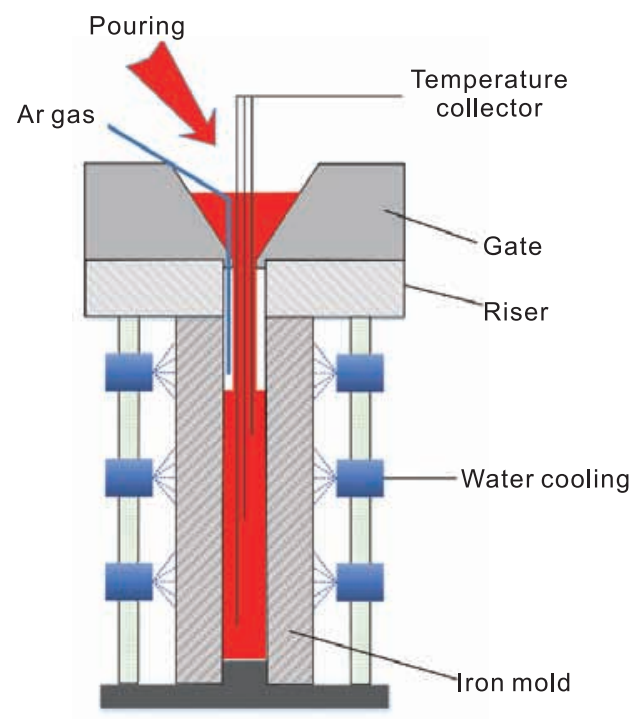

Fig. 1: Schematic diagram of near-rapid solidification device
MIK-R4000D multi-channel temperature collector was used for temperature detection; meanwhile, the high-purity argon gas was fed into the mold to inhibit the oxidation of the alloy melt. The near-rapid solidification was realized by continuously cooling the iron mold with circulating water, and the cooling rate was about $200 \mathrm{~K} \cdot \mathrm{s}^{-1}$. Finally, the slab ingots with a size of $200 \mathrm{~mm} \times 150$ $\mathrm{mm} \times 15 \mathrm{~mm}$ were obtained. All samples were cut for the microstructural analysis of as-cast and two-stage homogenized $\left(490{ }^{\circ} \mathrm{C} / 16 \mathrm{~h}\right.$ and $530{ }^{\circ} \mathrm{C} / 16 \mathrm{~h}$ ) alloys, respectively. The chemical compositions for the samples are listed in Table 1.

Table 1: Chemical compositions of Al-Cu-Li alloys (wt.\%)

\begin{tabular}{cccccccc} 
No. & $\mathrm{Cu}$ & $\mathrm{Mg}$ & $\mathrm{Mn}$ & $\mathrm{Zn}$ & $\mathrm{Zr}$ & $\mathrm{Li}$ & $\mathrm{Al}$ \\
\hline$\# 1$ & 3.84 & 0.47 & 0.31 & 0.51 & 0.13 & 1.49 & Bal. \\
$\# 2$ & 3.85 & 0.47 & 0.32 & 0.51 & 0.11 & 2.51 & Bal. \\
$\# 3$ & 3.83 & 0.46 & 0.32 & 0.52 & 0.12 & 3.50 & Bal. \\
$\# 4$ & 3.86 & 0.48 & 0.32 & 0.51 & 0.12 & 4.49 & Bal. \\
\hline
\end{tabular}

The microstructure of the alloys was analyzed by the combination of optical microscopy (OM, GX71, OLYMPUS, JP) and scanning electron microscopy (SEM, Quanta 200FEG, FEI, USA). In addition, energy dispersive spectroscopy (EDS, Quanta 200FEG, FEI, USA), X-ray diffraction (XRD, Empyrean, Panalytical, NL), and X-ray photoelectron spectroscopy (XPS, ESCALAB 250Xi, ThermoFisher, USA) were used together to determine the chemical composition and the precipitation phases in the microstructure. The density tests of the alloys were conducted using a high precision digital display density meter (QL-202GR). Image J software was used to analyze the volume fractions of the precipitated phase in the microstructure. Moreover, Pandat software was used to calculate the phase diagrams and the solidified paths of the alloys.

\section{Results and discussion}

Firstly, the phase diagrams and the solidified paths of the Al3.85 wt. $\% \mathrm{Cu}-x \operatorname{Li}[x=1.5,2.5,3.5,4.5$ (wt.\%)] alloys were calculated by the Pandat software, as shown in Fig. 2. It can be concluded from Fig. 2 that the addition of Li element can effectively change the solidification behavior of the alloys including the solidified paths and the composition of precipitated phases. When the Li content reaches $1.5 \mathrm{wt} \%$, the $\mathrm{Al}_{2} \mathrm{CuLi}$ and $\mathrm{Al}_{7} \mathrm{Cu}_{4} \mathrm{Li}$ are preferentially precipitated from the $\alpha-\mathrm{Al}$ and the liquid phase. Moreover, the $\mathrm{Al}_{2} \mathrm{CuLi}$ and $\mathrm{Al}_{6} \mathrm{CuLi}_{3}$ appear in the alloy with $2.5 \mathrm{wt} . \% \mathrm{Li}$ content, while only the $\mathrm{Al}_{6} \mathrm{CuLi}_{3}$ appears in the alloy when the Li content reaches 3.5wt.\%. In addition, $\mathrm{Al}_{3} \mathrm{Li}$ and $\mathrm{Al}_{6} \mathrm{CuLi}_{3}$ appear in the alloy with $4.5 \mathrm{wt} . \% \mathrm{Li}$ (Fig. 2a). The specific transition process of precipitated phases from alloys with 0 to $4.5 \mathrm{wt} . \%$ Li contents can be summed up as:

$$
\begin{aligned}
& \mathrm{Al}_{2} \mathrm{Cu} \rightarrow \mathrm{Al}_{7} \mathrm{Cu}_{4} \mathrm{Li} \rightarrow \mathrm{Al}_{2} \mathrm{CuLi} \rightarrow \mathrm{Al}_{6} \mathrm{CuLi}_{3} \\
& \rightarrow \mathrm{Al}_{6} \mathrm{CuLi}_{3}+(\mathrm{Al}, \mathrm{Li})
\end{aligned}
$$


(a)

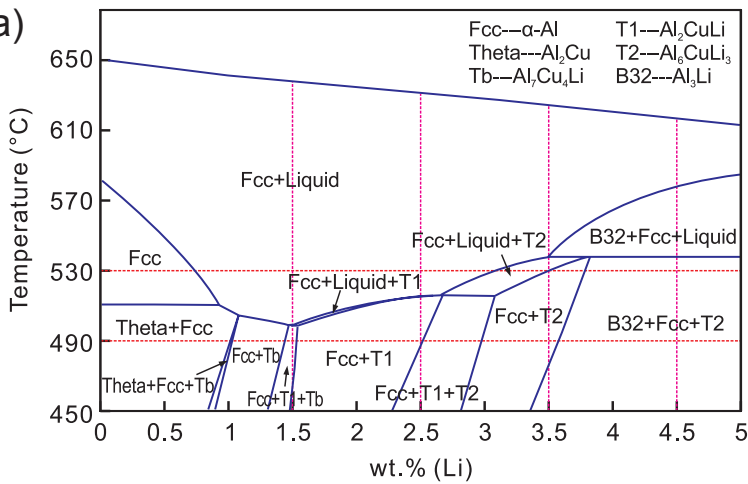

(c)

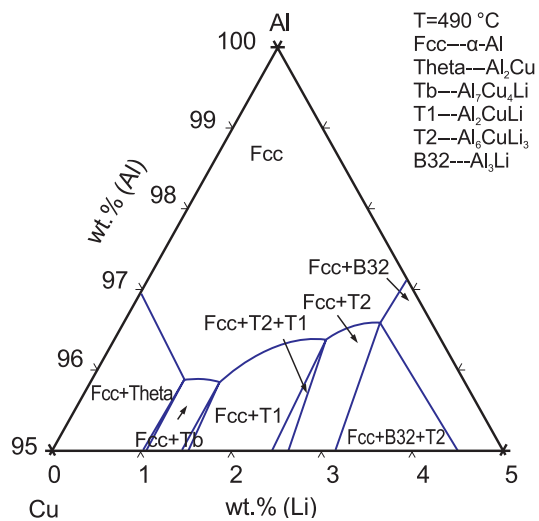

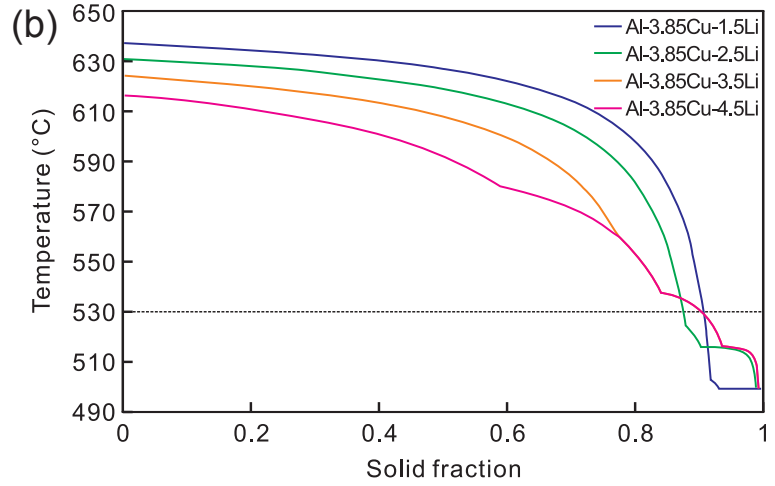

(d)

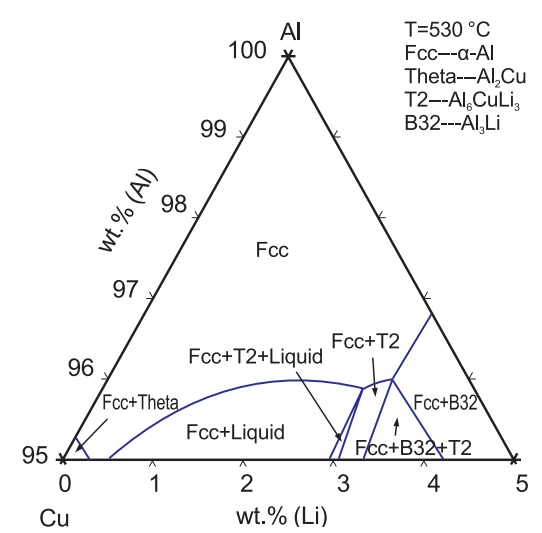

Fig. 2: Solidification behavior of Al-Cu-Li alloys: (a) and (b) are the phase diagrams and the solidified paths, respectively; (c) and (d) are the isothermal cross sections at 490 and $530^{\circ} \mathrm{C}$, respectively

Figure 2(b) also shows that when the Li content increases, the melting point of the alloys decreases, while the phase transition temperature increases accordingly. The phase diagrams shown in Fig. 2 also provide references for the temperature setting of homogenizing heat treatment. Although most of the precipitates can be dissolved at around $530{ }^{\circ} \mathrm{C}^{[23]}$, there still exists a tendency of over burning. Therefore, the two-stage homogenization heat treatment $\left(490{ }^{\circ} \mathrm{C} / 16 \mathrm{~h}\right.$ and $530{ }^{\circ} \mathrm{C} / 16 \mathrm{~h}$ ) was determined, which is of great significance in the microstructural improvement. In addition, the isothermal section phase diagrams at 490 and $530{ }^{\circ} \mathrm{C}$ of $\mathrm{Al}-\mathrm{Cu}-\mathrm{Li}$ alloys demonstrated in Figs. 2 ( $\mathrm{c}$ and d) indicate that the $\mathrm{Al}_{3} \mathrm{Li}$ and $\mathrm{Al}_{6} \mathrm{CuLi}_{3}$ phases cannot be completely eliminated after the homogenization heat treatment.

As shown in Fig. 3, the microstructural morphology of the alloys varies greatly with the Li content. By comparison, it can be obtained that the microstructures are closer to the equiaxed grains in the alloys with the Li content of $1.5 \mathrm{wt} . \%$ and $2.5 \mathrm{wt} . \%$, and the dendritic crystals in 3.5wt.\% and 4.5wt.\% alloys. Apparently, the grain sizes of the alloys with lower Li contents (Figs. 3a and 3b) are larger than those with higher Li contents (Figs. 3c and 3e); furthermore, the secondary dendrites do not appear in the alloys with lower Li contents (Figs. 3a and 3b), but they are developed in the alloys with higher Li contents (Figs. 3c and 3e). This is due to the diffusion transport of $\mathrm{Li}$ from the aluminum dendrites to the interdendritic region with the increase of Li during the near-rapid solidification process ${ }^{[24-26]}$. The measurement results and statistics of the densities of alloys and the volume fraction of precipitated phases in the alloys with different Li contents are shown in Table 2. It is clear that, with the increase of Li content, the densities of alloys significantly decrease; meanwhile, the volume fractions of precipitated phases drastically increase. Noteworthily, when the Li content reaches 1.5wt.\%-2.5wt.\%, the precipitated phases are relatively few and discontinuously distributed within the matrix $\alpha$-Al or at the grain boundaries, as shown in Figs. 3(a, b); additionally, the precipitated phases are mainly $\mathrm{Al}_{2} \mathrm{CuLi}$ and $\mathrm{Al}_{7} \mathrm{Cu}_{4} \mathrm{Li}$, looking at the combination of Fig. 2(a) and Eq. (1). This is because the near-rapid solidification can effectively promote the solid solubility of $\mathrm{Li}$ and $\mathrm{Cu}$ in the matrix $\alpha-\mathrm{Al}$ phase and reduce the volume fraction of the precipitated phases. Besides, by combining Fig. 2, Eq. (1) and Figs. 3(c, e), it can be concluded that with the increase of Li content, the precipitated phases transform accordingly and accumulate at the grain boundaries instead of within the matrix of $\alpha-\mathrm{Al}$. When the $\mathrm{Li}$ content reaches $3.5 \mathrm{wt} . \%$, the precipitated phases are mainly $\mathrm{Al}_{2} \mathrm{CuLi}$ and $\mathrm{Al}_{6} \mathrm{CuLi}_{3}$, which show a thick lamellar or rodlike morphology (Figs. 3c, 3d). When the Li content is $4.5 \mathrm{wt} . \%$, the precipitated phases form a grid morphology and are mainly composed of the eutectic phase of $\mathrm{Al}_{6} \mathrm{CuLi}_{3}$ and (Al, Li) (Figs. 3e, 3f).

The microstructure and energy spectrum results of alloys with different Li contents after the two-stage homogenization treatment $\left(490{ }^{\circ} \mathrm{C} / 16 \mathrm{~h}\right.$ and $\left.530{ }^{\circ} \mathrm{C} / 16 \mathrm{~h}\right)$ are shown in Fig. 4 and Table 3. It can be found that when the Li content is $1.5 \mathrm{wt} . \%-$ $2.5 \mathrm{wt} . \%$, the precipitated phases at the grain boundaries disappear after the homogenization heat treatment, with only a 


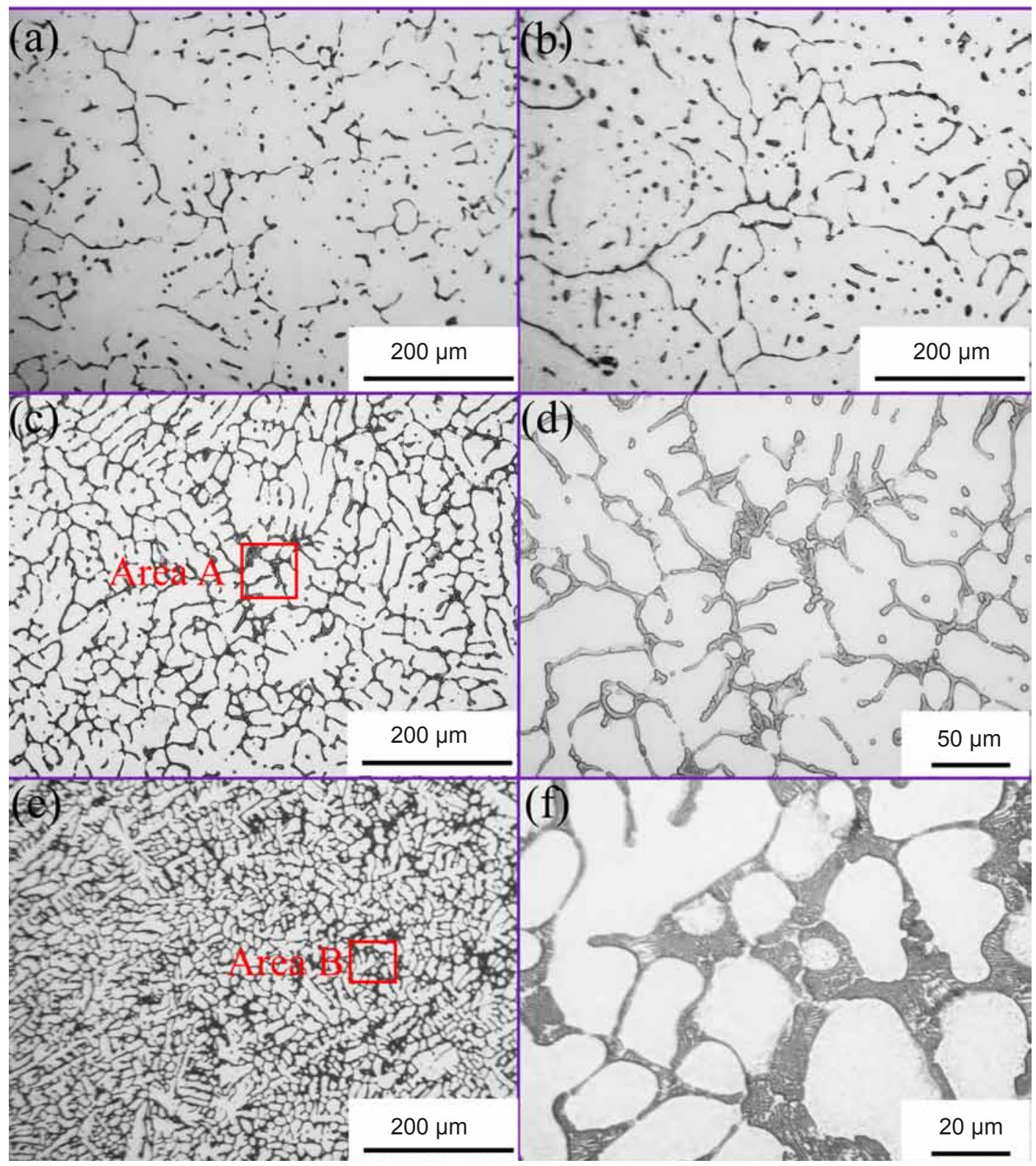

Fig. 3: Microstructural morphologies of as-cast alloys with different Li contents: (a) \#1; (b) \#2; (c) \#3; (d) locally enlarged image of Area A; (e) \#4; (f) locally enlarged image of Area B

Table 2: Densities of alloys and volume fractions of precipitates

\begin{tabular}{ccc|} 
No. & $\begin{array}{c}\text { Density } \\
\boldsymbol{\rho}\left(\mathbf{g} \cdot \mathbf{c m}^{-3}\right)\end{array}$ & $\begin{array}{c}\text { Volume fractions of precipitates } \\
(\%)\end{array}$ \\
\hline$\# 1$ & 2.67 & 20.4 \\
$\# 2$ & 2.62 & 20.8 \\
$\# 3$ & 2.58 & 22.2 \\
$\# 4$ & 2.53 & 23.8 \\
\hline
\end{tabular}

few phases left at the triangular cross boundaries, as shown in the Circles I and III of Figs. 4(a, b). When the Li content reaches $3.5 \mathrm{wt} . \%-4.5 \mathrm{wt} . \%$, the grain boundaries can be homogenized instead of dissolved, as shown in Figs. 4(c, d). This is because the melting points of precipitated phases in the alloys with lower Li contents (1.5wt.\%-2.5wt.\%) are lower than the alloys with higher Li contents (3.5wt.\%-4.5wt.\%). Additionally, when the Li content is $1.5 \mathrm{wt} . \%$, the precipitated phases at grain boundaries are dissolved completely by the heat treatment; while a large number of acicular and lamellar $\mathrm{Al}_{2} \mathrm{CuLi}^{\text {[27] }}$ precipitates appear in the matrix as shown in Circle II in Fig. 4(a) and Table 3. This is because the precipitated phases in the \#1 alloy are mainly $\mathrm{Al}_{7} \mathrm{Cu}_{4} \mathrm{Li}$, which is a metastable phase with a low solution temperature. By the two-stage homogenization heat treatment, $\mathrm{Al}_{7} \mathrm{Cu}_{4} \mathrm{Li}$ can be dissolved and lead to an increase in $\mathrm{Li}$ content in the matrix, so that many acicular and lamellar $\mathrm{Al}_{2} \mathrm{CuLi}$ precipitates form. In regards to the homogenized microstructure in the alloys with $2.5 \mathrm{wt} . \% \mathrm{Li}$ content, most of the grain boundaries can be effectively dissolved to form the acicular or lamellar precipitates as shown in Circle IV of Fig. 4(b), but some discontinuous precipitated phases are still left at the triangular cross boundaries. This is because the precipitated 


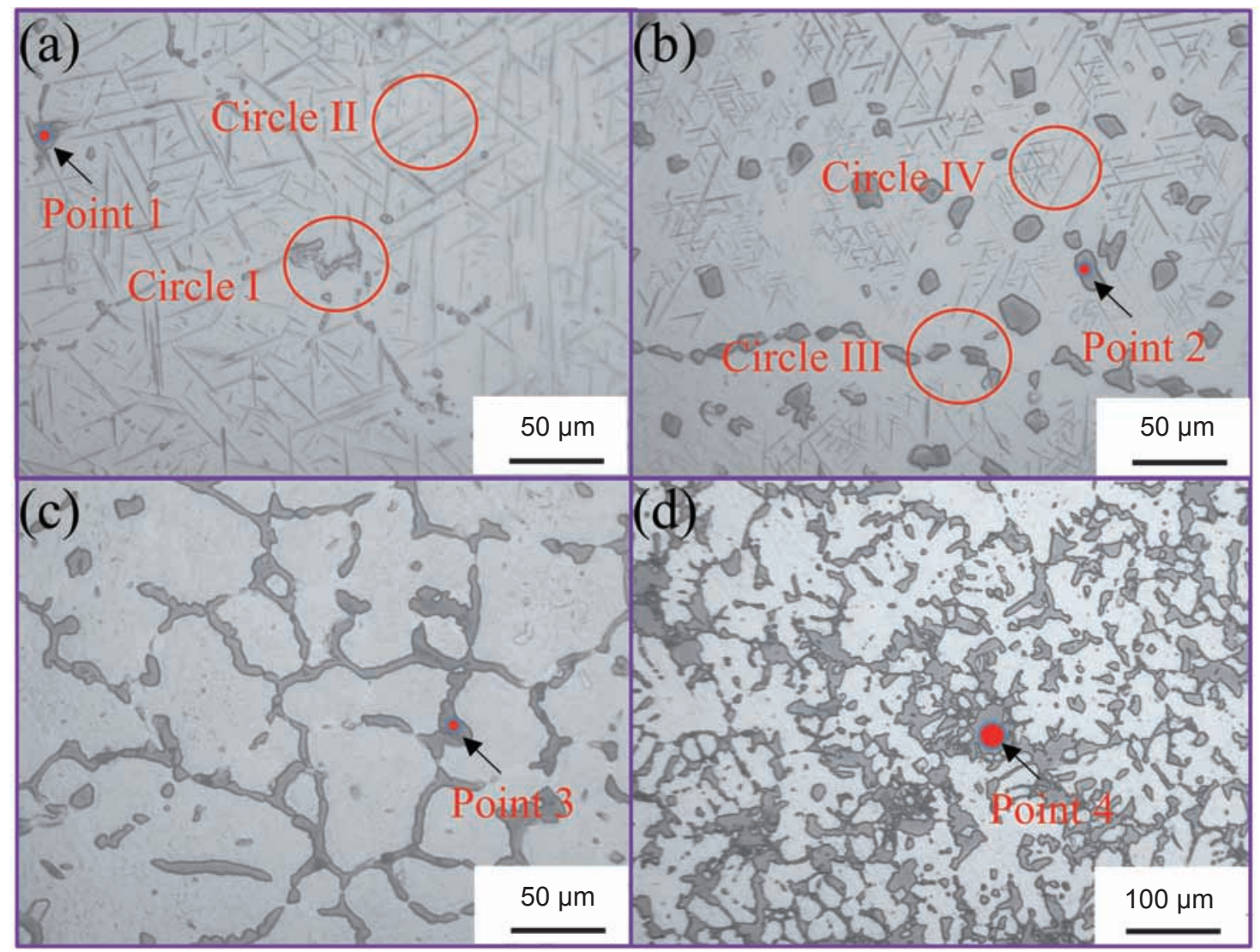

Fig. 4: Microstructural morphologies of homogenized alloys with different Li contents: (a) \#1; (b) \#2; (c) \#3; (d) \#4 (Note: Points 1-4 are the energy spectrum points; Circles I and III are the residual granular $\mathrm{Al}_{2} \mathrm{CuLi}$ phases; Circles II and IV are the acicular and lamellar $\mathrm{Al}_{2} \mathrm{CuLi}$ precipitates reconstituted in the matrix)

phases are mainly the combination of $\mathrm{Al}_{7} \mathrm{Cu}_{4} \mathrm{Li}$ and $\mathrm{Al}_{2} \mathrm{CuLi}$. After the heat treatment, the $\mathrm{Al}_{7} \mathrm{Cu}_{4} \mathrm{Li}$ can be preferentially dissolved, while the $\mathrm{Al}_{2} \mathrm{CuLi}$ has some difficulties to be remelted due to its high melting temperature. As a result, acicular and lamellar $\mathrm{Al}_{2} \mathrm{CuLi}$ precipitates appear in the matrix, while a few granular $\mathrm{Al}_{2} \mathrm{CuLi}$ will be left at the grain boundaries. Likewise, with respect to the alloys with $3.5 \mathrm{wt} . \%-4.5 \mathrm{wt} . \% \mathrm{Li}$ contents, the $\mathrm{Al}_{2} \mathrm{CuLi}, \mathrm{Al}_{6} \mathrm{CuLi}_{3}$ and $(\mathrm{Al}, \mathrm{Li})$ phases, with a higher solution temperature, are difficult to completely eliminate, resulting in the residue at grain boundaries after heat treatment [Figs. 4(c, d) and Table 3]. However, compared to the microstructure in Fig. 3, by the two-stage homogenization heat treatment, the precipitated

Table 3: Energy spectrum results of as-cast and homogenized microstructures for Figs. 4 and 5 (at.\%)

\begin{tabular}{cccccc} 
Point & Mn & $\mathrm{Cu}$ & $\mathrm{Mg}$ & $\mathrm{Zn}$ & $\mathrm{Al}$ \\
\hline 1 & 0.07 & 33.67 & 0.10 & 0.08 & 66.08 \\
2 & 0.65 & 31.66 & 0.91 & 0.12 & 66.66 \\
3 & 0.35 & 26.88 & 0.86 & 0.20 & 71.71 \\
4 & 0.46 & 17.92 & 0.77 & 0.18 & 80.67 \\
5 & - & 14.12 & 0.89 & - & 84.99 \\
6 & 7.52 & 9.55 & 0.32 & 9.62 & 72.99 \\
7 & - & 8.80 & - & - & 91.20 \\
\hline
\end{tabular}

phases at the boundaries and within the matrix are homogenized effectively, instead of accumulating. These results also have a strong relationship with the ratio of copper to lithium, as the $\mathrm{Li}$ element increases ${ }^{[28,29]}$.

To analyze the microstructural evolution of the alloys with high Li content (4.5wt.\%), the microstructural scanning photos and the energy spectrum results of as-cast and homogenized microstructure for \#4 samples are shown in Fig. 5 and Table 3, respectively. By the combination of Figs. 5(a, b) and Table 3, it can be obtained that when Li content reaches $4.5 \mathrm{wt} . \%$, the precipitated phases containing more $\mathrm{Cu}$ element are mainly the $\mathrm{Al}_{6} \mathrm{CuLi}_{3}$ and $\mathrm{Al}_{3} \mathrm{Li}^{[10]}$ appearing in the as-cast alloys, while the new precipitated phases with less $\mathrm{Cu}$ element will occur under the two-stage homogenization process as Point 7 in Fig. 5(b) ${ }^{[13,30]}$. The different ratio of copper to lithium will also lead to corresponding changes in the quantity and shape of $\mathrm{Al}_{3} \mathrm{Li}$ during the solidification process as well as the homogenization process ${ }^{[31]}$. Additionally, some precipitated phases containing $\mathrm{Mg}$, such as $\mathrm{Al}_{7} \mathrm{Cu}_{3} \mathrm{Mg}_{6}{ }^{[32]}$, appear in the as-cast alloys as shown in Point 5 in Fig. 5(a), but disappear in the homogenized alloys. Meanwhile, the precipitated phases with $\mathrm{Zn}$ and $\mathrm{Mn}$ elements will be formed by the heat treatment as indicated by Point 6 in Fig. 5(b).

In order to analyze the microstructural evolution process, XRD measurement was performed to determine the components of the precipitated phases in as-cast and homogenized microstructure, and the results are shown in Fig. 6. By comparing the phases in the as-cast alloys of \#1 and \#4 (Fig. 6), it can be found that when 


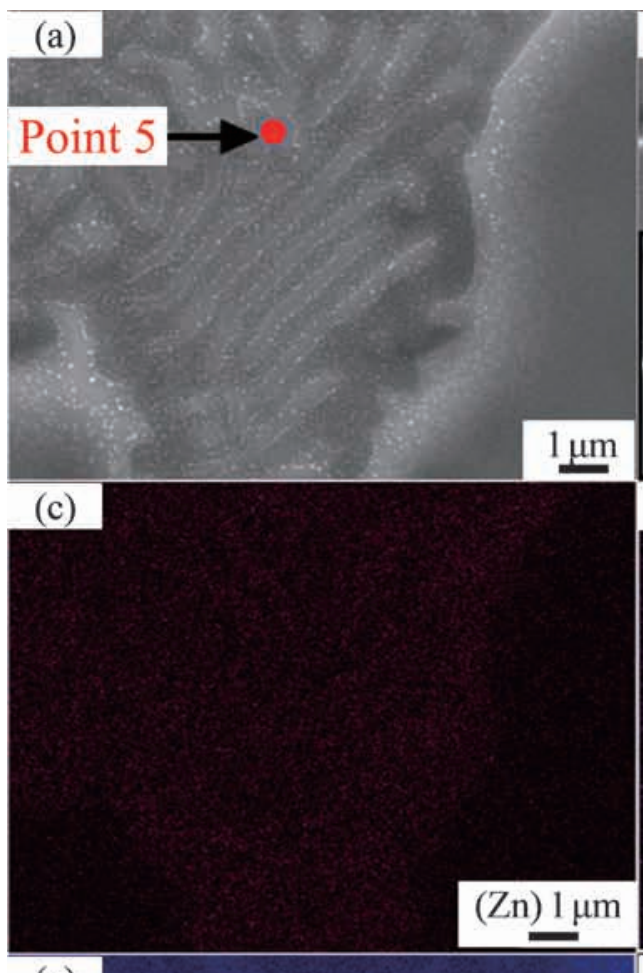

(b)

(f)

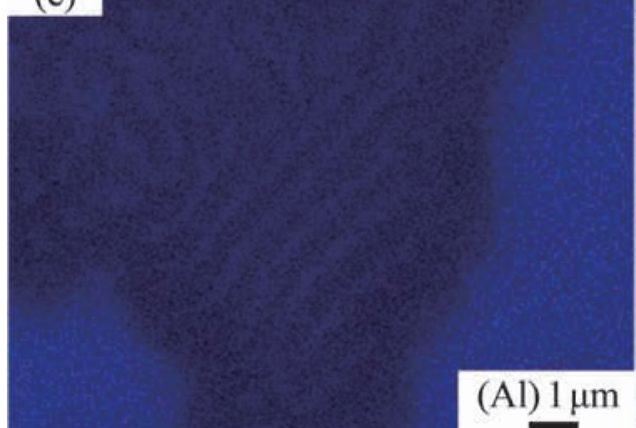

(g)

(b)

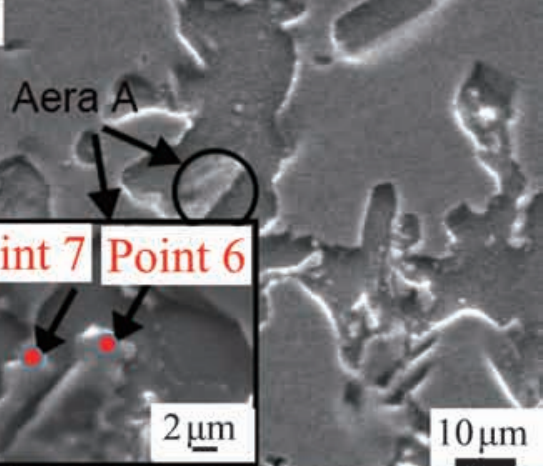

(d)

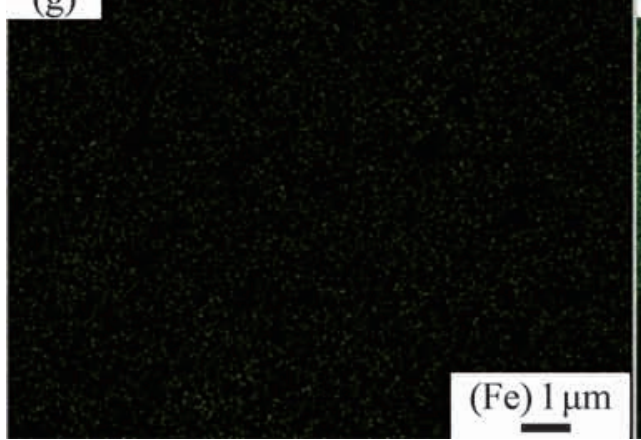

(h)

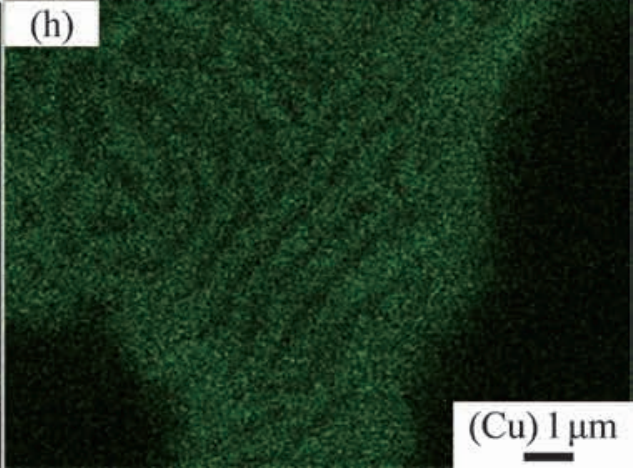

Fig. 5: Microstructural scanning photos of as-cast and homogenized microstructure for \#4 samples: (a) as-cast microstructure; (b) homogenized microstructure; (c), (d), (e), (f), (g), (h) are the map scanning of (a) for the elements of $\mathrm{Zn}, \mathrm{Mg}, \mathrm{Al}, \mathrm{Mn}, \mathrm{Fe}, \mathrm{Cu}$, respectively (Note: Points 5-7 are the energy spectrum points)

the $\mathrm{Li}$ content is $1.5 \mathrm{wt} . \%$, the precipitated phases in the as-cast alloys are mainly the metastable phase $\mathrm{Al}_{7} \mathrm{Cu}_{4} \mathrm{Li}^{[33]}$ and stable phase $\mathrm{Al}_{2} \mathrm{CuLi}$, which are formed at the grain boundary due to the higher ratio of $\mathrm{Cu}$ to $\mathrm{Li}$ during the near-rapid solidification. In this case, the $\mathrm{Cu}$ content is relatively high and the excess $\mathrm{Cu}$ element can produce the metastable phase $\mathrm{AlCu}_{3}$. After the homogenization heat treatment, it can be clearly seen that the $\mathrm{Al}_{7} \mathrm{Cu}_{4} \mathrm{Li}$ and $\mathrm{AlCu}_{3}$ are dissolved effectively, with the $\mathrm{Al}_{2} \mathrm{CuLi}$ left at the boundaries. In other words, the metastable phases with lower dissolving temperature can be dissolved by the two-stage homogenization heat treatment, and form the stable phases fixed in the matrix $\alpha-\mathrm{Al}{ }^{[34]}$. However, when $\mathrm{Li}$ content increases to $4.5 \mathrm{wt} . \%$, due to the strong combination ability of $\mathrm{Li}$ and $\mathrm{Al}$, as well as the rapid cooling rate during the solidification, the solution ability of $\mathrm{Cu}$ element in the $\alpha$-Al is improved greatly. Hence, the precipitated phases in the ascast alloys with $4.5 \mathrm{wt} . \% \mathrm{Li}$ are mainly $\mathrm{Al}_{6} \mathrm{CuLi}_{3}$ and $\mathrm{Al}_{3} \mathrm{Li}$, which have higher dissolving temperatures than the $\mathrm{Al}_{7} \mathrm{Cu}_{4} \mathrm{Li}$ 


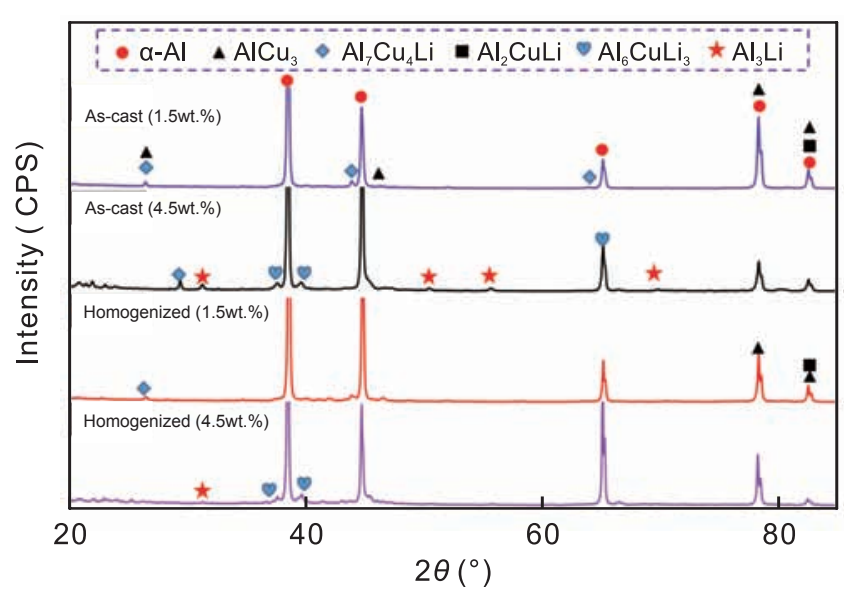

Fig. 6: XRD results of as-cast and homogenized microstructures for alloys with $1.5 \mathrm{wt} . \%$ and $4.5 \mathrm{wt} . \% \mathrm{Li}$

and $\mathrm{AlCu}_{3}$. As a result, the precipitated phases $\mathrm{Al}_{6} \mathrm{CuLi}_{3}$ and $\mathrm{Al}_{3} \mathrm{Li}$ cannot be eliminated completely by the heat treatment, but the residual precipitated phases distribute uniformly along the grain boundaries, which lead to a homogeneous microstructure.

Therefore, by the near-rapid solidification, the increase of $\mathrm{Li}$ content in $\mathrm{Al}-\mathrm{Cu}-\mathrm{Li}$ alloys improves the solution ability of $\mathrm{Cu}$ element in the matrix $\alpha-\mathrm{Al}$, leading to the appearance of precipitated phases with a higher ratio of Li to Al. In addition, in regards to the alloys with different Li contents, the coupling of near-rapid solidification and the two-stage homogenization heat treatment can bring about the increase of solution abilities of $\mathrm{Cu}$ and $\mathrm{Li}$ in the matrix phase, the change of the microstructural morphology and grain sizes, the redistribution of precipitated phases, the effective redissolution of the metastable phases, and the homogenized and stable microstructure in the alloys.

\section{Conclusion}

Comparative studies were carried out on the microstructural evolution of the Al-Cu-Li alloys with different Li contents, which are prepared by the near-rapid solidification and twostage homogenization treatment. The current findings indicate that the increase of Li content can change the morphology and content of the microstructures, such as refining the primary dendrite, increasing the solution ability of $\mathrm{Cu}$ in matrix $\alpha$-Al phases and the content of secondary dendrites. In addition, it will lead to the evolutions from the low melting point phases to the high melting point phases under the nearrapid solidification process. It is of great significance that by the coupling of near-rapid solidification and the two-stage homogenization treatment, the metastable phases $\mathrm{Al}_{7} \mathrm{Cu}_{4} \mathrm{Li}$ and $\mathrm{AlCu}_{3}$ with lower dissolving temperature can be redissolved effectively in the $\mathrm{Al}-\mathrm{Cu}-\mathrm{Li}$ alloys containing any $\mathrm{Li}$ content. Additionally, the stable phases such as $\mathrm{Al}_{2} \mathrm{CuLi}, \mathrm{Al}_{6} \mathrm{CuLi}_{3}$ and $\mathrm{Al}_{3} \mathrm{Li}$ with the higher dissolving temperature can be redistributed uniformly along the grain boundaries instead of redissolved completely. The study has demonstrated that the homogenized and stable microstructure in the higher Licontent alloys can be achieved by combining the near-rapid solidification with a proper homogenization treatment.

\section{Acknowledgements}

This research was financially supported by the National Key Research and Development Program of China (Grant No. 2017YFA0403804), and the National Natural Science Foundation of China (Grant No. 51425402).

\section{References}

[1] Dorin T, Deschamps A, Geuser F, et al. Quantification and modelling of the microstructure/strength relationship by tailoring the morphological parameters of the $\mathrm{T} 1$ phase in an Al-Cu-Li alloy. Acta Materialia, 2014, 75: 134-146.

[2] SHi C L, Xi X K. NMR investigation of atomic bonding properties in Al-Li alloys. Intermetallics, 2014, 51: 64-67.

[3] Rioja R J, Liu J. The evolution of Al-Li base products for aerospace and space applications. Metallurgical and Materials Transactions A, 2012, 43 (9): 3325-3337.

[4] Evans J W. The evolution of technology for light metals over the last 50 years: Al, Mg, and Li. JOM, 2007, 59 (2): 30-38.

[5] Williams J C, Starke E A. Progress in structural materials for aerospace systems. Acta Mater, 2003, 51: 5775-5799.

[6] Lavernia E J, Srivatsan T S, Mohamed F A. Strength, deformation, fracture behaviour and ductility of aluminium-lithium alloys. Journal of Materials Science, 1990, 25 (2): 1137-1158.

[7] Wu L, Zhou C, Li X F, et al. Microstructural evolution and mechanical properties of cast high-Li-content $\mathrm{TiB}_{2} / \mathrm{Al}-\mathrm{Li}$ $\mathrm{Cu}$ composite during heat treatment. Journal of Alloys and Compounds, 2018, 739: 270-279.

[8] Wang S C, Starink M J. Precipitates and intermetallic phases in precipitation hardening $\mathrm{Al}-\mathrm{Cu}-\mathrm{Mg}-(\mathrm{Li})$ based alloys. International Materials Reviews, 2005, 50: 193-215.

[9] Xu X, Song T, Fan Z, et al. Microstructure and dislocation strengthening of Sc microalloyed 2099 Al-Li alloy. Rare Metal Materials and Engineering, 2012, 41: 621-624.

[10] Wu L, Li X F, Han G Y, et al. Precipitation behavior of the high-Li-content in-situ $\mathrm{TiB}_{2} / \mathrm{Al}-\mathrm{Li}$-Cu composite. Materials Characterization, 2017, 132: 215-222.

[11] Balducci E, Ceschini L, Messieri S. High temperature tensile tests of the lightweight 2099 and $2055 \mathrm{Al}-\mathrm{Cu}-\mathrm{Li}$ alloy: A comparison. JOM, 2018, 70 (11): 2716-2725.

[12] Zhang F, Shen J, Yan X D, et al. Homogenization heat treatment of 2099 Al-Li alloy. Rare Metals, 2014, 33 (1): 28-36.

[13] Shanmugasundaram T, Murty B S, Sarma V S. Development of ultrafine grained high strength $\mathrm{Al}-\mathrm{Cu}$ alloy by cryorolling. Scripta Materialia, 2006, 54 (12): 2013-2017.

[14] Kim W J, Chung C S, Ma D S, et al. Optimization of strength and ductility of $2024 \mathrm{Al}$ by equal channel angular pressing (ECAP) and post-ECAP aging. Scripta Materialia, 2003, 49 (4): 333-338.

[15] Deng Y J, Huang G J, Cao L F, et al. Improvement of strength and ductility of Al-Cu-Li alloy through cryogenic rolling followed by aging. Transactions of Nonferrous Metals Society of China, 2017, 27 (9): 1920-1927.

[16] Yang S L, Shen L, Yan X D, et al. Homogenization treatment parameter optimization and microstructural evolution of $\mathrm{Al}-\mathrm{Cu}-\mathrm{Li}$ alloy. Rare Metal Materials \& Engineering, 2017, 46(1): 28-34. 
[17] Yang S L, Shen J, Zhang Y A, et al. Processing maps and microstructural evolution of $\mathrm{Al}-\mathrm{Cu}-\mathrm{Li}$ alloy during hot deformation. Rare Metals, 2017, 6: 1-8.

[18] Lavernia E J, Ayers J D, Srivatsan T S. Rapid solidification processing with specific application to aluminium alloy. International Materials Reviews, 1992, 37 (1): 1-44.

[19] Wang Y, Lorimer G W, Sale F R. Microstructural development during consolidation of rapidly solidified Al-Fe-V-Si powder by VHP, extrusion and rolling. Scripta Metallurgica et Materialia, 1994, 31 (10): 1337-1342.

[20] Tang Y P, Tan D Q, Li W X, et al. Preparation of Al-Fe-VSi alloy by spray co-deposition with added its over-sprayed powders. Journal of Alloys and Compounds, 2007, 439 (1-2): 103-108.

[21] Liu Y L, Luo L, Shun M Z, et al. Microstructure and mechanical properties of Al-5.5Fe-1.1V-0.6Si alloy solidified under nearrapid cooling and with Ce addition. Rare Metals, 2016, 37 (12): 1070-1075.

[22] Liu Y L, Liu M, Luo L, et al. The influence of cooling rate and alloying elements on the microstructure refinement of Al-5Fe alloy. Orlando: TMS Annual Meeting: Light Metals, 2015: 271-275.

[23] Donnadieu P, Shao Y, Geuser F, et al. Atomic structure of T1 precipitates in Al-Li-Cu alloys revisited with HAADF-STEM imaging and small-angle X-ray scattering. Acta Materialia, 2011, 59 (2): 462-472.

[24] Jia P F, Cao Y H, Geng Y D, et al. Effects of DC current on the phase transformation in 7050 alloy during homogenization. Materials Characterization, 2014, 96: 21-27.

[25] Radetić T, Popovic M, Romhanji E. Microstructure evolution of a modified AA5083 aluminum alloy during a multistage homogenization treatment. Materials Characterization, 2012, 65: $16-27$
[26] Qing L, Zhu R, Li J, et al. Microstructural evolution of Mg, Ag and $\mathrm{Zn}$ micro-alloyed Al-Cu-Li alloy during homogenization. Transactions of Nonferrous Metals Society of China, 2016, 26(3): 607-619.

[27] Lloyd D J. Particle reinforced aluminium and magnesium matrix composites. International Materials Reviews, 1994, 39(1): 1-23.

[28] Li J F, Liu P L, Chen Y L, et al. Microstructure and mechanical properties of $\mathrm{Mg}, \mathrm{Ag}$ and $\mathrm{Zn}$ multi-microalloyed $\mathrm{Al}-(3.2-3.8) \mathrm{Cu}-$ (1.0-1.4) Li alloys. Transactions of Nonferrous Metals Society of China, 2015, 25 (7): 2103-2112.

[29] Mørtsell E A, Marioara C D, Andersen S J, et al. The effects and behaviour of $\mathrm{Li}$ and $\mathrm{Cu}$ alloying agents in lean $\mathrm{Al}-\mathrm{Mg}-\mathrm{Si}$ alloys. Journal of Alloys and Compounds, 2017, 699: 235-242.

[30] Zhang L, Zheng Z Q, Li J F, et al. Microstructural evolution and mechanical properties of a new Al-Cu-Li-X alloy at different solution temperatures. Rare Metals, 2016 (1):1-8.

[31] Kabisch O, Gille W, Krol J. The effect of copper addition on the structure and strength of an Al-Li alloy. Materials \& Design, 1997, 18 (4-6): 385-388.

[32] Ivanov R, Deschamps A, Geuser F. High throughput evaluation of the effect of $\mathrm{Mg}$ concentration on natural ageing of Al-Cu-Li(Mg) alloys. Scripta Materialia, 2018, 150: 156-159.

[33] Araullo-Peters V, Gault B, Geuser F, et al. Microstructural evolution during ageing of Al-Cu-Li-X alloys. Acta Materialia, 2014, 66: 199-208.

[34] Liu G, Gong M, Xie D, et al. Structures and mechanical properties of $\mathrm{Al}_{-} \mathrm{Al}_{2} \mathrm{Cu}$ Interfaces. JOM, 2019, 71(4): 12001208. 